\title{
INDICADORES DE DESEMPENHO AMBIENTAL EVIDENCIADOS NOS RELATÓRIOS DE SUSTENTABILIDADE: UMA ANÁLISE À LUZ DE ATRIBUTOS DE QUALIDADE
}

\author{
Guillermina Tannuri \\ Mestranda em Contabilidade pela Universidade Federal de Santa Catarina - UFSC \\ guilletannuri@hotmail.com \\ Hans Michael Van Bellen \\ Professor da Universidade Federal de Santa Catarina - UFSC \\ hansmichael@cse.ufsc.br
}

\section{RESUMO}

Os relatórios de sustentabilidade são publicados pelas companhias por diferentes motivos, para mostrar seu desempenho ambiental positivo - teoria do disclosure voluntário-; alterar seu status de legitimidade - teoria da legitimidade- ou dar resposta a grupos de interesse - teoria do stakeholder. Assim, nem todas as informações são evidenciadas com o mesmo nível de transparência e qualidade. O objetivo desta pesquisa consiste em analisar os indicadores de desempenho ambiental evidenciados nos relatórios de sustentabilidade das empresas listadas no Índice de Sustentabilidade Empresarial (ISE), tendo como base os seguintes atributos de qualidade: compreensibilidade, integridade, neutralidade $\mathrm{e}$ comparabilidade. Para isso, optou-se por uma pesquisa do tipo descritiva, predominantemente qualitativa, e valeu-se de elementos da técnica de análise de conteúdo. Foram selecionados 35 relatórios dos quais foram analisados, para cada relatório, 30 indicadores ambientais evidenciados de acordo com a diretriz GRI. Os resultados demonstraram que os indicadores com um maior nível de qualidade foram aqueles que informaram sobre as emissões de gases de efeito estufa; sobre a disposição dos resíduos; e sobre o consumo de água e energia. $\mathrm{O}$ atributo de qualidade mais comprometido nas evidenciações dos 30 indicadores foi a comparabilidade, principalmente em decorrência de: omissão de metas sólidas; carência de pontos de referência externos; e falta de padronização na evidenciação dos indicadores. Conclui-se que as organizações precisam aperfeiçoar os processos relacionados a estas questões para garantir a clareza, o equilíbrio e a relevância das informações divulgadas.

Palavras-chave: Atributos de qualidade; Evidenciação ambiental; Indicadores de desempenho ambiental; Relatórios de sustentabilidade.

\section{ENVIRONMENTAL PERFORMANCE INDICATORS SHOWN IN THE REPORTING OF SUSTAINABILITY: AN ANALYSIS OF THE LIGHT OF QUALITY ATTRIBUTES}

\begin{abstract}
Sustainability reports are published by companies for different reasons: to show their positive environmental performance - theory of voluntary disclosure; to change their legitimacy status legitimacy theory - or to respond to stakeholders - stakeholder theory. Therefore, not all information is indicated with the same level of transparency and quality. The objective of this research is to analyze the environmental performance indicators shown in sustainability reports of companies listed on the Corporate Sustainability Index (ISE). To accomplish this, the following quality attributes were looked into: responsiveness, integrity, neutrality and comparability. Descriptive research was conducted; predominantly qualitative, and drew on elements of the technique of content analysis. There were 35 reports selected, from which were analyzed a total of 30 environmental indicators disclosed in accordance with GRI guidelines. The results showed that the indicators with a higher level of quality were those reporting on emissions of greenhouse gases; on the disposal of waste and on water and energy consumption. The most common quality attribute in the disclosures of the 30 indicators was comparability. This is primarily due to the omission of targets, a lack of external reference points, and the lack of standardization in the disclosure of the indicators. It was concluded that organizations need to continue working to ensure clarity, balance and relevance of the information disclosed.
\end{abstract}

Key-words: Environmental disclosure; Environmental performance indicators; Quality attributes; Sustainability reporting. 


\section{INTRODUÇÃO}

Tendo como base a publicação do relatório de Brundtland (1987) e da Cúpula da Terra Rio92, os membros de organismos internacionais, chamaram os mandatários dos países e os dirigentes das empresas para criarem a consciência social, apelando para a utilização moderada dos recursos naturais e para a redução da pobreza humana. Nesse cenário, a partir de 1990, as empresas, principalmente as mais visíveis e influentes, se tornaram alvo para mostrar seu compromisso com o meio ambiente e informar sobre as atividades empreendidas, visando evitar as "externalidades" decorrentes da produção industrial. Assim, os líderes dos negócios reconheceram a necessidade de responder a essas pressões, de uma forma que seja boa para o negócio e que também satisfaça as necessidades dos stakeholders. Isso acabou resultando na publicação de relatórios ambientais, sociais e/ou de sustentabilidade (Isaksson e Steimle, 2009; Kolk, 2003).

No início, existia confusão entre as organizações sobre o que informar, mas, com o tempo, iniciativas de caráter internacional surgiram para padronizar os relatórios, por meio de diretrizes de publicação, entre estas, tem se destacado, nos últimos anos, a Global Reporting Initiative (GRI). Os relatórios abrangem a sustentabilidade como um todo, e, quando se trata do desempenho ambiental, da forma de mensurá-lo e apresentá-lo se faz, geralmente, por meio de indicadores. Nesse sentido, Daub (2007) explica que os indicadores representam os dados concretos sobre o desempenho da empresa em relação à sustentabilidade e, portanto, devem ser considerados de suma importância. Com o intuito de auxiliar as organizações nesse aspecto, a diretriz GRI apresenta quais indicadores devem ser reportados por elas, além de fornecer orientações para a compilação dos dados pertinentes.

No entanto, tratando-se de publicações voluntárias, nem todos os indicadores são evidenciados com o mesmo nível de transparência e qualidade. Nos últimos anos, os relatórios ambientais receberam críticas por parte dos stakeholders, a pesquisa de Christofi, Christofi e Sisaye (2012) apontou a dificuldade persistente em analisar, quantificar e comparar as informações, até mesmo por especialistas da indústria e analistas financeiros. Apesar do significativo crescimento de relatórios publicados no mundo, a qualidade do disclosure, no entanto, não aumentou, existindo poucas evidências de progresso na integração dos impactos ambientais em decisões da gestão (Epstein, 2008).

A finalidade principal de um relatório ambiental deve ser a de poder responder, de forma coerente, as preocupações e os interesses dos usuários. Para que isso seja possível, os relatórios precisam estar fundados em alguns pilares básicos, certos atributos, tais como a relevância, a confiabilidade, a compreensibilidade e a comparabilidade; que farão com que as informações fornecidas se tornem úteis e credíveis aos olhos dos usuários (Azzone et al., 1997; Unctad, 2004). Acredita-se que um relatório elaborado com base nesses, e outros atributos de qualidade, permitirá às empresas afiançar sua relação com os investidores, clientes, fornecedores e demais interessados nas atividades corporativas.

Nesse contexto, a consecução desta pesquisa se propõe responder à seguinte questão: Os indicadores de desempenho ambiental, evidenciados nos relatórios de sustentabilidade, fornecem informações coerentes com os atributos de qualidade? Com o intuito de responder a questão problema exposta, esta pesquisa visa alcançar o seguinte objetivo geral: realizar uma análise dos indicadores de desempenho ambiental, evidenciados nos relatórios de sustentabilidade das empresas listadas no Índice de Sustentabilidade Empresarial, à luz de atributos de qualidade. Para alcançar esse objetivo, foram traçados os seguintes objetivos específicos: a) descrever as características gerais dos relatórios de sustentabilidade das empresas integrantes do ISE; b) identificar, por meio da revisão bibliográfica, atributos de qualidade da informação ambiental; c) verificar nos relatórios de sustentabilidade os indicadores de desempenho ambiental evidenciados segundo a diretriz GRI; d) analisar os indicadores, a partir de atributos de qualidade previamente estabelecidos.

Este trabalho está estruturado em cinco seções, começando por esta introdução, seguida, na seção 2, pela revisão da literatura; na seção 3, é apresentada a metodologia utilizada para alcançar

Revista de Gestão Social e Ambiental - RGSA, São Paulo, v. 8, n. 1, p. 2-19, jan./abr., 2014. 
os objetivos da pesquisa, enquanto, no capítulo 4, se dispõe a apresentação e análise dos dados e a discussão dos resultados, para, por fim, no capítulo 5, serem expostas as considerações finais.

\section{FUNDAMENTAÇÃO TEÓRICA}

A base teórica desta pesquisa aborda quatro tópicos considerados relevantes para sua consecução, a começar pelo tema relatórios de sustentabilidade; seguido pelos achados de pesquisas anteriores sobre o assunto; logo, são tratados os atributos de qualidade inerentes às informações ambientais; e por último, são apresentados os conceitos e as características dos indicadores ambientais.

\subsection{Relatórios de sustentabilidade}

Os relatórios de sustentabilidade são definidos, pela World Business Council for Sustainable Development (WBCSD), como: "[...]os relatórios públicos [elaborados] pelas companhias para proporcionar aos stakeholders internos e externos uma imagem da posição e das atividades corporativas, nas dimensões econômica, ambiental e social" (WBCSD, 2002). De acordo com Daub (2007), trata-se de um relatório que deve conter informações quantitativas e qualitativas à medida que a companhia vai conseguindo melhorar sua eficácia e eficiência econômica, ambiental e social no período reportado, e passa a integrar esses aspectos em um sistema de gestão de sustentabilidade.

Quanto aos motivos que levam as empresas a evidenciarem seu comportamento ambiental, existem diferentes abordagens para explicá-los. Entre as teorias mais discutidas pela literatura especializada, se destacam a teoria do disclosure voluntário, a da legitimidade e a do stakeholder. A teoria do disclosure voluntário vaticina uma relação positiva entre o desempenho ambiental e o nível de evidenciação ambiental. De acordo com esta teoria, as empresas com um maior desempenho ambiental buscarão se distinguir da concorrência ao divulgarem informação favorável quanto à sua performance ambiental. Nesse sentido, as firmas com um desempenho ambiental inferior evidenciarão menos, buscando evadir a exposição negativa (Verrecchia, 1983 apud Dawkins e Fraas, 2011).

A teoria da legitimidade, por sua vez, alega que as organizações são capazes de fazer escolhas estratégicas para alterar seu status de legitimidade, adaptando suas atividades e mudando percepções. Assim, as organizações adotarão várias medidas, principalmente por meio da comunicação, para garantir que seu desempenho seja percebido como legítimo (Aerts e Cormier, 2009). De outro ponto de vista, a teoria do stakeholder "[...]trata sobre grupos e indivíduos que podem afetar a organização e sobre o comportamento gerencial adotado em resposta a estes grupos e indivíduos" (Freeman, 1984 p. 48 apud Lee, 2011).

Desde o primeiro relatório de conteúdo ambiental, publicado há mais de 30 anos, é cada vez maior o número de empresas que evidenciam, voluntariamente, informações sobre políticas, estratégias, metas, ações e resultados de índole ambiental. Essa evolução, pesquisada por Kolk (2004), se refere não somente a uma evolução em termos de quantidade, mas também no que tange ao conteúdo dos relatórios. O Brasil não escapou do auge da publicação de relatórios de sustentabilidade, de acordo com o site da Global Reporting Initiative (GRI, 2014), a quantidade de relatórios de sustentabilidade publicados por empresas brasileiras continuou aumentando nos últimos anos, em 2010 foram publicados 150 relatórios chegando em 226 no ano 2013.

\subsection{Críticas aos relatórios de sustentabilidade em pesquisas anteriores}

Com o crescente avanço da publicação de relatórios de sustentabilidade nos últimos anos, além das pesquisas sobre quantidade, um importante número de pesquisas, em diferentes países, se focou em avaliar o conteúdo e a qualidade desses relatórios. Mas, o aproveitamento dos relatórios ambientais como objeto de estudo não é algo recente, as primeiras pesquisas datam de 1970, e, já nessa época, esses relatórios recebiam duras críticas. Eram catalogados como documentos publicados para próprio benefício das organizações, além de conterem dados imprecisos e

Revista de Gestão Social e Ambiental - RGSA, São Paulo, v. 8, n. 1, p. 2-19, jan./abr., 2014. 
incompletos acerca do desempenho ambiental das mesmas (Dierkes e Preston, 1977; Wiseman, 1982).

Com o passar dos anos, era de se esperar que esses problemas fossem resolvidos, porém, apesar da inegável evolução que atravessaram os relatórios, as mesmas críticas perduram até hoje. Marshall e Brown (2003) realizaram uma análise taxonômica das métricas utilizadas por 79 companhias, e os resultados sugeriram que as métricas mais comumente usadas fornecem pouca informação sobre o desempenho futuro e que a maioria delas descreve o desempenho das operações, ao invés de descrever os impactos ambientais. Por fim, os autores concluíram que apesar dos esforços de padronização de iniciativas como a GRI, as evidenciações ambientais possuem diversos formatos de apresentação, sendo que essa variabilidade na forma, no estilo e conteúdo faz com que as comparações nos setores se tornem um desafio, se não algo impossível.

A pesquisa de Leszczynska (2012) avaliou o conteúdo de 29 relatórios de empresas multinacionais que abrangem o período 2005-2010, com o intuito de verificar sua utilidade para os acionistas. Os resultados apontaram uma evolução nos relatórios. Porém, o autor destacou que as empresas devem focar em melhorar a qualidade das informações ambientais, principalmente no que diz respeito ao equilíbrio e à objetividade, já que a maioria se concentra em informações positivas, omitindo o desempenho ruim e os projetos fracassados.

A qualidade das informações foi o foco da pesquisa de Vormedal e Ruud (2009),em que foram avaliadas as práticas de relatórios de sustentabilidade das 100 maiores empresas da Noruega. A análise dos relatórios voluntários abordou a responsabilidade social, os sistemas de gestão, códigos de conduta e a gestão da cadeia de fornecimento. Os resultados apontaram que a grande maioria das empresas reporta insatisfatoriamente as questões analisadas, tendo os autores concluído que isso se deve a uma aparente falta de "drivers" sociais para relatórios de sustentabilidade na Noruega.

Uma análise mais quantitativa foi conduzida por Roca e Searcy (2012), cujo objetivo consistiu em identificar os indicadores reportados nos relatórios de sustentabilidade de 94 empresas canadenses. Os resultados mostraram que os indicadores reportados divergem para cada setor, o que dificulta a comparabilidade entre as companhias. Quanto ao nível de evidenciação ambiental nos relatórios, o estudo de Saida (2009) comparou o disclosure ambiental de empresas americanas versus europeias, e chegou à conclusão que as empresas multinacionais europeias fornecem mais informação que as americanas. Desse modo, a nacionalidade das organizações parece provocar um efeito no nível de comunicação ambiental.

Já a análise de relatórios de responsabilidade social, elaborada pela empresa KPMG (2011), concluiu que a comunicação dos resultados é um desafio permanente para as companhias, sendo que ainda existe certo nível de inconsistência no formato e na acessibilidade dos relatórios, que, por enquanto, continua impactando a comparabilidade entre as empresas e os grupos industriais.

Embora os relatórios de sustentabilidade sejam percebidos como uma forma de as organizações oferecerem maior transparência nas questões socioambientais, Hopwood (2009) opina o contrário. De acordo com o autor, os relatórios podem, inclusive, reduzir os conhecimentos que se tem sobre as atividades ambientais das organizações, sendo que as empresas estão mais interessadas em aumentar sua legitimidade, bem como em construir uma imagem diferente por meio dos relatórios.

Outra crítica constante aos modelos de relatórios tem a ver com as estratégias adotadas pelas corporações, com o intuito de mostrar uma "realidade" não tão real. Gray (2006) e Milne, Tregidga e Walton (2009) criticam o uso sutil de imagens, metáforas e outros símbolos, nos quais as contradições entre crescimento econômico, por um lado, e natureza e meio ambiente, pelo outro, são comumente ignoradas. Assim, o estudo de Hrasky (2012) demonstrou que algumas empresas tentam atingir a necessária legitimidade pragmática utilizando um discurso visual poderoso, ao invés das ações, que são as que, necessariamente, sustentam a legitimidade moral. Por sua vez, a pesquisa de Cho, Roberts e Patten (2010) indicou que o disclosure ambiental das empresas com um 
desempenho mais fraco parece enfatizar as boas notícias, ofuscar as más notícias, e utilizar uma linguagem e um tom verbal que permitam manejar as impressões dos stakeholders.

\subsection{Os atributos de qualidade da informação ambiental}

Com a crescente crise de confiança que atravessou o mercado de capitais nos últimos anos, a qualidade dos dados publicados nos relatórios de sustentabilidade é de vital importância para lograr a credibilidade dos grupos de interesse e dos investidores, fornecendo, por meio destes, as respostas que eles procuram. Assim, tornou-se necessário que as empresas garantam a credibilidade e relevância do conteúdo dos relatórios, e, para isso, todas as informações, contidas nestes, deverão ser válidas, abrangentes, confiáveis e comparáveis (Leszczynska, 2012).

A aplicação de elevados padrões de qualidade melhorará a capacidade dos investidores de monitorar a empresa, ao proporcionar maior confiabilidade e comparabilidade dos relatórios, bem como uma melhor visão do desempenho da empresa (OECD, 2004). Para construir um disclosure transparente, as diretrizes de relatórios de sustentabilidade, desenvolvidas por organismos de reconhecimento global, definiram os principais atributos de qualidade requeridos nos relatórios, conforme apresentados na figura 1 .

\begin{tabular}{|c|l|}
\hline Atributos & \multicolumn{1}{c|}{ Descrição } \\
\hline $\begin{array}{c}\text { Contexto da } \\
\text { sustentabilidade }\end{array}$ & $\begin{array}{l}\text { O relatório deverá apresentar o desempenho da organização no contexto mais amplo da } \\
\text { sustentabilidade, envolvendo o desempenho no contexto dos limites relativos aos recursos } \\
\text { ambientais em nível setorial, local, regional ou global. }\end{array}$ \\
\hline $\begin{array}{c}\text { Compreensibilidade } \\
\text { /Clareza }\end{array}$ & $\begin{array}{l}\text { As informações devem ser compreensíveis, acessíveis e utilizáveis por todos os usuários. As } \\
\text { respostas desejadas deverão ser encontradas sem demasiado esforço, e apresentadas de } \\
\text { maneira clara para os stakeholders. }\end{array}$ \\
\hline Materialidade & $\begin{array}{l}\text { A materialidade determina a relevância e significância de um assunto para a organização e } \\
\text { seus stakeholders. É o limiar, a partir do qual um tema ou indicador se torna suficientemente } \\
\text { expressivo para ser relatado. }\end{array}$ \\
\hline $\begin{array}{c}\text { Equilíbrio/ } \\
\text { Neutralidade }\end{array}$ & $\begin{array}{l}\text { O conteúdo do relatório deverá retratar, de modo imparcial, o desempenho da organização, } \\
\text { sem omissões ou formatos que tendam a influenciar indevidamente o julgamento do leitor. } \\
\text { Deve incluir resultados tanto favoráveis quanto desfavoráveis. }\end{array}$ \\
\hline $\begin{array}{c}\text { Confiabilidade } \\
\text { Abrangência/ } \\
\text { Integridade }\end{array}$ & $\begin{array}{l}\text { A informação tem a qualidade de confiabilidade quando está livre de erro material e viés e } \\
\text { possa representar, fielmente, o que ela pretende representar ou o que, razoavelmente, se espera } \\
\text { que represente. }\end{array}$ \\
\hline $\begin{array}{c}\text { Capacidade de } \\
\text { resportura dos temas e indicadores relevantes deverá ser suficiente para refletir os impactos } \\
\text { organização no período analisado. }\end{array}$ \\
\hline $\begin{array}{l}\text { As informações deverão ser suficientemente precisas e detalhadas para que os stakeholders } \\
\text { avaliem o desempenho da organização relatora. }\end{array}$ \\
\hline $\begin{array}{l}\text { Os stakeholders que usarem o relatório deverão poder comparar as informações sobre o atual } \\
\text { desempenho ambiental da organização com o anterior, com seus objetivos e, na medida do } \\
\text { possível, com o desempenho de outras organizações. }\end{array}$ \\
\hline
\end{tabular}

Figura 1. Atributos que regem a qualidade dos relatórios de sustentabilidade

Fonte: Elaborado com base nas diretrizes da Unctad (2004), GRI (2006) e Accountability (2008)

De acordo com a Unctad (2004), as características qualitativas são os atributos que tornam as informações proporcionadas nos relatórios úteis para os usuários. Estas estipulam, ainda, o dever dos usuários de entender e empreender esforços para compreender as informações, mesmo que sejam complexas. Assim, as características qualitativas equilibram as exigências dos usuários e preparadores, de tal forma que seja rentável para ambos.

\subsection{Indicadores de desempenho ambiental}

Os indicadores ambientais são os encarregados de fornecer o suporte de informação adequado para permitir o julgamento de valor das alterações no ambiente, resultante das atividades, dos produtos ou serviços de uma organização, de preferência com base em um sistema de valores

Revista de Gestão Social e Ambiental - RGSA, São Paulo, v. 8, n. 1, p. 2-19, jan./abr., 2014. 
explícitos (Olsthoorn et al., 2001). De acordo com o Manual de Indicadores de Ecoeficiência da Unctad (2004), o objetivo dos indicadores é gerar informação sobre o desempenho ambiental de uma empresa, complementando as demonstrações financeiras, a fim de melhorar a qualidade da tomada de decisão. A informação é útil a uma gama de usuários, favorecendo a tomada de decisões sensatas, bem como a avaliação, inclusive preventiva, do impacto das decisões. Essa informação também é necessária para a prestação de contas, por parte da gestão, pelo uso dos recursos naturais que lhes foram confiados. Além disso, para os indicadores serem considerados úteis, devem satisfazer uma série de requisitos. Na figura 2, a seguir, são apresentados os requisitos definidos por Beloff e Beaver (2000).

- Simples e compreensíveis para uma variedade de públicos;

- Reprodutíveis e consistentes para comparar diferentes períodos, unidades de negócios, ou alternativas de decisão;

- Robustos (ex. "melhores" métricas devem, de fato, indicar um maior desempenho de sustentabilidade);

- Complementar os programas de regulamentação existentes;

- O custo-benefício em termos de coleta de dados - fazendo uso principalmente de dados já coletados / disponíveis para outros fins;

- Úteis para a tomada de decisão;

- Empilháveis ao longo da cadeia de suprimentos ou do ciclo de vida do produto;

- Escaláveis para múltiplas fronteiras de análise;

- Protetores de informações confidenciais.

Figura 2. Requerimentos dos indicadores de sustentabilidade

Fonte: Beloff e Beaver (2000).

Uma importante contribuição dos indicadores é que, se estes são aplicados ao longo de um período de tempo, podem ser usados para determinar uma tendência. Moldan, Janousková e Hák (2012), porém, entendem que, se estes forem em valores absolutos, não podem cumprir inteiramente esta função. Além disso, para os autores, os indicadores devem estar ligados a pontos de referência e metas, permitindo comparar as condições reais com um conjunto específico de condições de referência, ou seja, permite medir a distância entre a situação ambiental atual e a situação desejada.

\section{PROCEDIMENTOS METODOLÓGICOS}

Para o delineamento da pesquisa, optou-se por adotar uma abordagem descritiva e predominantemente qualitativa. A coleta de dados da pesquisa apoiou-se nos procedimentos de pesquisa bibliográfica e documental. Valeu-se da pesquisa bibliográfica, primordialmente, para a contextualização do problema de pesquisa e fundamentação teórica, servindo de base para a identificação e a interpretação dos atributos de qualidade procurados nos indicadores de desempenho ambiental. Quanto aos documentos, o primeiro coletado foi o Conjunto de Protocolos de Indicadores de Desempenho Ambiental da GRI versão G3 (2006). A escolha da diretriz GRI como ponto de referência para a análise justifica-se por sua representatividade internacional, além do fato de ser genérica e aplicável a um amplo espectro de organizações (Moneva, Archel e Correa, 2006). Além disso, de acordo com a pesquisa de Corporate Register (2011), o Brasil é considerado um dos países líderes, no mundo, em adotar a diretriz GRI, ficando atrás, apenas, da Espanha, de Portugal e da África do Sul. Os indicadores de desempenho ambiental estipulados pela diretriz, e analisados nesta pesquisa, constituem um total de trinta e abordam os diferentes aspectos da sustentabilidade ambiental das organizações, como apresentado na figura 3 seguinte. 


\begin{tabular}{|c|c|c|}
\hline ASPECTO & INDICADOR & \\
\hline Materiais & $\begin{array}{l}\text { EN1 - Materiais usados por peso e volume; } \\
\text { EN2 - Percentual dos materiais usados provenientes de reciclagem. }\end{array}$ & $\begin{array}{l}\text { Essencial } \\
\text { Essencial }\end{array}$ \\
\hline Energia & $\begin{array}{l}\text { EN3 - Consumo de energia direta discriminado por fonte de energia primária; } \\
\text { EN4 - Consumo de energia indireta discriminado por fonte de energia primária; } \\
\text { EN5 - Energia economizada devido a melhorias em conservação e eficiência; } \\
\text { EN6 - Iniciativas para fornecer produtos e serviços com baixo consumo de } \\
\text { energia, ou que usem energia gerada por recursos renováveis, e a redução na } \\
\text { necessidade de energia resultante dessas iniciativas; } \\
\text { EN7 - Iniciativas para reduzir o consumo de energia indireta e as reduções } \\
\text { obtidas. }\end{array}$ & $\begin{array}{l}\text { Essencial } \\
\text { Essencial } \\
\text { Adicional } \\
\text { Adicional }\end{array}$ \\
\hline Água & $\begin{array}{l}\text { EN8 - Total de retirada de água por fonte; } \\
\text { EN9 - Fontes hídricas significativamente afetadas por retirada de água; } \\
\text { EN10 - Percentual e volume total de água reciclada e reutilizada. }\end{array}$ & $\begin{array}{l}\text { Essencial } \\
\text { Adicional } \\
\text { Adicional }\end{array}$ \\
\hline Biodiversidade & $\begin{array}{l}\text { EN11 - Localização e tamanho da área possuída, arrendada ou administrada } \\
\text { dentro de áreas protegidas, ou adjacentes a elas, e áreas de alto índice de } \\
\text { biodiversidade fora das áreas protegidas; } \\
\text { EN12 - Descrição de impactos significativos na biodiversidade de atividades, } \\
\text { produtos e serviços em áreas protegidas e em áreas de alto índice de } \\
\text { biodiversidade fora das áreas protegidas; } \\
\text { EN13 - Habitats protegidos ou restaurados; } \\
\text { EN14 - Estratégias, medidas em vigor e planos futuros para a gestão de } \\
\text { impactos na biodiversidade; } \\
\text { EN15 - Número de espécies na Lista Vermelha da IUCN e em listas nacionais } \\
\text { de conservação com habitats em áreas afetadas por operações, discriminadas } \\
\text { por nível de risco de extinção. }\end{array}$ & $\begin{array}{l}\text { Adicional } \\
\text { Adicional } \\
\text { Adicional }\end{array}$ \\
\hline $\begin{array}{l}\text { Emissões, } \\
\text { efluentes e } \\
\text { resíduos }\end{array}$ & $\begin{array}{l}\text { EN16 - Total de emissões diretas e indiretas de gases causadores do efeito } \\
\text { estufa, por peso; } \\
\text { EN17 - Outras emissões indiretas relevantes de gases causadores do efeito } \\
\text { estufa, por peso; } \\
\text { EN18 - Iniciativas para reduzir as emissões de gases causadores do efeito estufa } \\
\text { e as reduções obtidas; } \\
\text { EN19 - Emissões de substâncias destruidoras da camada de ozônio, por peso; } \\
\text { EN20 - Nox, Sox e outras emissões atmosféricas significativas, por tipo e peso; } \\
\text { EN21 - Descarte total de água, por qualidade e destinação; } \\
\text { EN22 - Peso total de resíduos, por tipo e método de disposição; } \\
\text { EN23 - Número e volume total de derramamentos significativos; } \\
\text { EN24 - Peso de resíduos transportados, importados, exportados ou tratados } \\
\text { considerados perigosos nos termos da Convenção da Basileia - Anexos I, II, III } \\
\text { e VIII, e percentual de carregamentos de resíduos transportados } \\
\text { internacionalmente. } \\
\text { EN25 - Identificação, tamanho, status de proteção e índice de biodiversidade de } \\
\text { corpos d'água e habitats relacionados, significativamente afetados por descartes } \\
\text { de água e drenagem, realizados pela organização relatora. }\end{array}$ & $\begin{array}{l}\text { Essencial } \\
\text { Essencial } \\
\text { Adicional } \\
\text { Essencial } \\
\text { Essencial } \\
\text { Essencial } \\
\text { Essencial } \\
\text { Essencial } \\
\text { Adicional }\end{array}$ \\
\hline $\begin{array}{l}\text { Produtos e } \\
\text { serviços }\end{array}$ & $\begin{array}{l}\text { EN26 - Iniciativas para mitigar os impactos ambientais de produtos e serviços e } \\
\text { a extensão da redução desses impactos; } \\
\text { EN27 - Percentual de produtos e suas embalagens recuperados em relação ao } \\
\text { total de produtos vendidos, por categoria de produto. }\end{array}$ & $\begin{array}{l}\text { Essencial } \\
\text { Essencial }\end{array}$ \\
\hline Conformidade & $\begin{array}{l}\text { EN28 - Valor monetário de multas significativas e número total de sanções não } \\
\text { monetárias, resultantes da não conformidade com as leis e os regulamentos } \\
\text { ambientais. }\end{array}$ & Essencial \\
\hline Transporte & $\begin{array}{l}\text { EN29 - Impactos ambientais significativos do transporte de produtos e outros } \\
\text { bens e materiais utilizados nas operações da organização, bem como do } \\
\text { transporte dos trabalhadores. }\end{array}$ & Adicional \\
\hline Geral & EN30 - Total de investimentos e gastos em proteção ambiental, por tipo. & Adicional \\
\hline
\end{tabular}

Figura 3.Indicadores de Desempenho Ambiental GRI

Fonte: GRI, 2006

Como se observa na figura, os indicadores encontram-se classificados em essenciais ou adicionais. Os indicadores essenciais são considerados relevantes para todas as organizações, já os 
adicionais representam práticas emergentes ou tratam de temas que podem ser relevantes para algumas organizações, mas não para outras. Para fins desta pesquisa, o fato de um indicador ser essencial ou adicional não fez diferença na análise.

O segundo tipo de documentos coletados foram os relatórios anuais e/ou de sustentabilidade do ano 2011 das empresas integrantes da carteira 2011/12 do Índice de Sustentabilidade Empresarial (ISE). Foram escolhidas essas empresas porque se pressupôs que, como integrantes de um índice de sustentabilidade, todas iriam divulgar um relatório de sustentabilidade, de onde seriam coletadas as informações para esta pesquisa. Ainda, uma vez que o fim desta pesquisa é analisar os indicadores num sentido de excelência, se escolhidos outros relatórios poderia ter se caído no risco de analisar relatórios muito incompletos e apenas razoáveis, portanto considerou-se que estes 35 relatórios constituíam um número relevante para o propósito desta pesquisa.

Para a análise, partiu-se do pressuposto que os indicadores em véspera de satisfazer às necessidades de informação de seus usuários, devem conter os atributos de compreensibilidade, integridade, neutralidade e comparabilidade. Embora o conjunto de atributos de qualidade da informação ambiental não se reduza a esses quatro, esse corte foi necessário pelo fato de que a maioria dos atributos é aplicável para a análise da qualidade do relatório como um todo, como nos casos dos atributos da materialidade e confiabilidade, e não apenas para os indicadores de desempenho. Portanto, foram escolhidos aqueles atributos admissíveis para analisar a qualidade de cada indicador individualmente. Além disso, uma vez que esses atributos são genéricos e desejáveis para qualquer tipo de informação, não apenas a ambiental, foram operacionalizados de forma a se adaptarem à análise da informação fornecida, essencialmente, pelos indicadores estipulados.

$\mathrm{Na}$ continuação, na figura 4, são apresentados os atributos de qualidade operacionalizados, baseados na diretriz GRI (2006), na norma AA1000 (2008), no Manual para os Preparadores e Usuários de Indicadores de Ecoeficiência (2004), e nas pesquisas de Leszczynska (2012) e de Isaksson e Steimle (2009).

\begin{tabular}{|c|c|}
\hline Atributos & Operacionalização dos atributos de qualidade \\
\hline 1) Compreensibilidade & $\begin{array}{l}\text { - A informação contida no indicador (quantitativa ou qualitativa) é apresentada de forma } \\
\text { simples, clara e fácil de compreender pelos usuários dos relatórios? } \\
\text { - A informação fornecida responde claramente a questão específica do indicador } \\
\text { relatado? } \\
\text { - É evitado um vocabulário muito técnico, siglas ou outros termos que possam ser pouco } \\
\text { conhecidos pelos usuários? }\end{array}$ \\
\hline 2) Integridade & $\begin{array}{l}\text { - A informação apresentada é íntegra, contemplando todos os elementos requisitados } \\
\text { pelo indicador? } \\
\text { - Não são omitidos dados relevantes, cuja omissão possa tornar a informação deficiente } \\
\text { ou distorcida? }\end{array}$ \\
\hline 3) Neutr & $\begin{array}{l}\text { - A informação contida no indicador reflete tanto os aspectos favoráveis como os } \\
\text { desfavoráveis do desempenho ambiental da organização? } \\
\text { - O indicador permite aos usuários verificar as tendências positivas bem como as } \\
\text { negativas ano a ano? } \\
\text { - As questões relevantes positivas são enfatizadas em igual medida que as negativas? }\end{array}$ \\
\hline 4) Comparabilidade & $\begin{array}{l}\text { - O indicador permite avaliar o desempenho ambiental da organização em comparação } \\
\text { com outras empresas do mesmo setor? } \\
\text { - São reportadas comparações com o desempenho médio do mercado, medidas } \\
\text { nacionais, leis e/ou o melhor desempenho do setor (benchmarks externos)? } \\
\text { - São reportadas metas e objetivos (benchmarks internos), de tal forma que seja possível } \\
\text { relacionar os níveis atuais dos indicadores às metas predefinidas? }\end{array}$ \\
\hline
\end{tabular}

Figura 4. Atributos de qualidade utilizados na análise

Fonte: Elaborado pela pesquisadora com base na literatura

A análise dos indicadores partiu pela procura do primeiro indicador nos relatórios coletados. Uma vez achado o indicador, foi realizada uma leitura atenta e interpretativa dos dados divulgados, com o intuito de verificar se o indicador atendia ou não a cada um dos itens dos atributos de 
qualidade. Isto foi tabulado numa planilha, na qual, se fez uma contagem da quantidade de empresas que atenderam cada um dos atributos do indicador analisado. Essa análise foi realizada com os trinta indicadores. No final, se fez uma tabela resumo, apresentada no tópico de resultados, a qual sintetiza quais os indicadores relatados com uma maior qualidade, ou seja, que tiveram um maior nível de atendimento dos atributos, e quais os atributos de qualidade menos atendidos no geral.

\section{APRESENTAÇÃO E ANÁLISE DOS RESULTADOS}

Esta seção está dividida em duas seções: (1) perfil das empresas do ISE e descrição das características gerais dos relatórios de sustentabilidade, e (2) análise da qualidade dos 30 indicadores de desempenho ambiental, de acordo com a diretriz GRI.

\subsection{Apresentação das empresas integrantes do ISE e das características gerais de seus relatórios de sustentabilidade}

Das empresas que fazem parte da carteira ISE 2011/2012, foram analisados os relatórios de 35 das 37 listadas. Duas empresas foram retiradas da análise, já que seus relatórios não foram confeccionados em concordância com a diretriz GRI. Do total de empresas, uma quantidade significativa (dezesseis) pertence ao grupo classificado como recursos naturais renováveis, com destaque para as empresas de energia elétrica. Isso pode ser justificado pelo fato de a Agência Nacional de Energia Elétrica (Aneel) exigir que todas as empresas do setor publiquem relatórios de sustentabilidade. O segundo setor em destaque é o financeiro, composto de oito empresas; seguido pelo grupo de matérias-primas e insumos, com quatro empresas; e três empresas do rubro de serviços. O grupo se completa com duas empresas de transporte e duas que exploram recursos naturais não-renováveis.

Para a consecução da análise, usou-se como base os relatórios de sustentabilidade publicados pelas empresas já referidas, resultando apropriado expor uma descrição geral, apresentada na Tabela 1 , na continuação.

Tabela 1. Características dos relatórios de sustentabilidade selecionados

\begin{tabular}{|c|c|c|c|c|}
\hline Empresa & $\begin{array}{l}\text { Nível de } \\
\text { aplicação } \\
\text { GRI }\end{array}$ & $\begin{array}{l}\text { Tamanho do } \\
\text { relatório total } \\
\text { (páginas) }\end{array}$ & $\begin{array}{c}\text { Proporção da dimensão } \\
\text { ambiental em relação ao } \\
\text { relatório total }\end{array}$ & $\begin{array}{l}\text { Indicadores ambientais } \\
\text { relatados (quantidade) }\end{array}$ \\
\hline AES Tietê & $\mathrm{B}$ & 111 & $5 \%$ & 15 \\
\hline Anhanguera & $\mathrm{B}$ & 104 & $4 \%$ & 7 \\
\hline Banco do Brasil & $\mathrm{A}+$ & 209 & $5 \%$ & 19 \\
\hline Bicbanco & $\mathrm{B}+$ & 112 & $8 \%$ & 19 \\
\hline Bradesco & $\mathrm{A}+$ & 86 & $13 \%$ & 29 \\
\hline Braskem & $\mathrm{B}+$ & 108 & $13 \%$ & 15 \\
\hline BRF Brasil Foods & $\mathrm{A}+$ & 81 & $15 \%$ & 23 \\
\hline $\mathrm{CCR}$ & $\mathrm{B}$ & 36 & $22 \%$ & 13 \\
\hline Cemig & $\mathrm{A}+$ & 157 & $10 \%$ & 28 \\
\hline Cesp & $\mathrm{B}+$ & 132 & $8 \%$ & 17 \\
\hline Coelce & $\mathrm{A}$ & 140 & $7 \%$ & 30 \\
\hline Copasa & $\mathrm{B}$ & 162 & $4 \%$ & 9 \\
\hline Copel & $\mathrm{A}$ & 128 & $9 \%$ & 30 \\
\hline CPFL Energia & $\mathrm{A}+$ & 288 & $11 \%$ & 27 \\
\hline Duratex & $\mathrm{A}+$ & 105 & $5 \%$ & 15 \\
\hline Ecorodovias & $\mathrm{B}$ & 119 & $8 \%$ & 22 \\
\hline Eletrobras & $\mathrm{B}$ & 169 & $8 \%$ & 21 \\
\hline Eletropaulo & $\mathrm{B}$ & 136 & $7 \%$ & 15 \\
\hline Embraer & $\mathrm{B}$ & 132 & $7 \%$ & 21 \\
\hline Energias do Brasil & $\mathrm{A}+$ & 152 & $12 \%$ & 30 \\
\hline Even & $\mathrm{B}+$ & 111 & $8 \%$ & 12 \\
\hline Fibria & $\mathrm{A}+$ & 192 & $19 \%$ & 30 \\
\hline
\end{tabular}

Revista de Gestão Social e Ambiental - RGSA, São Paulo, v. 8, n. 1, p. 2-19, jan./abr., 2014. 


\begin{tabular}{c|c|c|c|c}
\hline Itaúsa & $\mathrm{A}+$ & 114 & $8 \%$ & $5 \%$ \\
\hline Itaú Unibanco & $\mathrm{A}+$ & 208 & $6 \%$ & 29 \\
\hline Light S/A & $\mathrm{A}$ & 174 & $10 \%$ & 24 \\
\hline Natura & $\mathrm{A}+$ & 134 & $6 \%$ & 30 \\
\hline Redecard & $\mathrm{B}$ & 93 & $7 \%$ & 12 \\
\hline Sabesp & $\mathrm{B}$ & 96 & $10 \%$ & 15 \\
\hline Santander & $\mathrm{A}+$ & 72 & $7 \%$ & 28 \\
\hline SulAmérica & $\mathrm{B}+$ & 96 & $16 \%$ & 9 \\
\hline Suzano Papel & $\mathrm{B}+$ & 108 & $2 \%$ & 22 \\
\hline Telemar & $\mathrm{C}$ & 128 & $15 \%$ & 22 \\
\hline Tim Part S/A & $\mathrm{B}+$ & 40 & $12 \%$ & 23 \\
\hline Tractebel & $\mathrm{A}+$ & 186 & $17 \%$ & $\mathbf{2 1}$ \\
\hline Vale & $\mathrm{A}+$ & 121 & $\mathbf{9 \%}$ & \\
\hline Médias & - & $\mathbf{1 3 0}$ & & \\
\hline
\end{tabular}

Fonte: Elaborado pela pesquisadora

Dos dados apresentados na tabela anterior, cabe destaque alguns pontos. No que diz respeito ao tamanho total, os relatórios podem ser estratificados de acordo com sua quantidade de páginas. Assim, 23\% dos relatórios contêm menos de 100 páginas; 69\% possuem entre 100 e 200 páginas; e $9 \%$, mais de 200 páginas. Constatou-se, por meio dessa análise, que a grande maioria dos relatórios possui mais de cem páginas, sofrendo esse tamanho uma constante crítica na literatura, já que levanta a dúvida se são lidos em sua totalidade pelos interessados, e da sua utilidade, pois muitas vezes a informação excessiva é utilizada para justificar impactos negativos, ao invés de comunicar a real situação da organização.

Avançando nos conteúdos dos relatórios, especificamente, na parte analisada nesta pesquisa, quer seja, o desempenho ambiental, chama a atenção que esta informação ocupe, em todos os casos analisados, menos de um quarto do relatório. Depreende-se da tabela que a extensão representa uma média de 12 páginas, ou seja, em média, apenas $9 \%$ do relatório é destinado à evidenciação dos indicadores de desempenho ambiental, sendo que $91 \%$ do conteúdo restante se refere a informações sobre o desempenho econômico e social, a governança corporativa, gestão ambiental etc. Cabe mencionar que o tamanho da dimensão ambiental não se relaciona sempre com o tamanho total do relatório, isto é, existem organizações que dedicam mais espaço no relatório para informar sobre seu desempenho ambiental, quando outras estão mais preocupadas em evidenciar sobre a gestão social ou econômica. Um exemplo é o caso da Suzano Papel, que possui um relatório de 108 páginas, sendo 17 utilizadas para evidenciar a dimensão ambiental, correspondente a 16\% do total, já a Embraer detém um relatório de 162 páginas, dedicando nove delas aos indicadores ambientais, o que equivale apenas a $6 \%$ do relatório. A média de 21 indicadores evidenciados sobre um total de 30 pode ser considerada elevada, se bem, é de se notar, que existem diferenças entre essas empresas, variando de apenas sete indicadores evidenciados pela empresa Anhanguera até o total de 30 reportados por Coelce, Copel, Energias do Brasil, Fibria e Natura.

No que diz respeito à aplicação da diretriz GRI, refere-se ao fato de os relatores declararem o nível de aplicação da Estrutura de Relatórios da GRI, o que implica uma comunicação clara e transparente de quais elementos da estrutura foram aplicados na elaboração do relatório. $\mathrm{O}$ sistema define três níveis de autodeclaração, C, B e A, sendo A o ponto mais alto, e, em caso que o relatório tenha contado com verificação externa, a organização poderá autodeclarar o símbolo (+) no nível correspondente (por exemplo, $\mathrm{C}+, \mathrm{B}+, \mathrm{A}+$ ). No entanto, um fato um tanto curioso é que para a autodeclaração do nível $\mathrm{B}$, por exemplo, somente exige-se a publicação de 20 indicadores de desempenho, abrangendo as três dimensões (econômica, ambiental e social), e tendo que informar, pelo menos, um indicador de uma dessas áreas. Aqui fica plantada uma perfeita situação de evidenciações positivas, de acordo com a teoria do disclosure voluntário, segundo a qual uma empresa que detenha fortes indicadores econômicos optará por evidenciá-los prioritariamente, tendo a opção de evidenciar apenas um indicador ambiental e um social e obter, mesmo assim, um nível de declaração B, um nível respeitado entre as empresas que aplicam a diretriz para a preparação dos 
relatórios. Um caso assim é o da Anhanguera, que, dos 30 indicadores de desempenho ambiental, evidenciou apenas cinco em forma integral e dois parcialmente, representando menos de um terço do total dessa área.

Quanto à auditoria externa, no total, foram verificados vinte relatórios, ficando, desse modo, quinze fora de qualquer tipo de verificação; um número consideravelmente alto para estas empresas que prometem ser líderes em práticas sustentáveis, fato pelo qual se esperava que a maioria fornecesse uma garantia do que está sendo informado.

\subsection{Apresentação da análise dos indicadores de desempenho ambiental}

Nesta subseção se inclui a análise dos trinta indicadores de desempenho ambiental realizada nas 35 empresas da seleção. A apresentação foi organizada observando os aspectos - materiais; energia; água; biodiversidade; emissões, efluentes e resíduos; produtos e serviços e transporte; e conformidade e geral -, que abrangem os indicadores relacionados a eles.

$\mathrm{Na}$ decorrência da análise, diversos foram os resultados obtidos para cada um dos indicadores. Esses resultados estão demonstrados de forma sucinta, na figura 5, que compreende o nível de qualidade por indicador, mostrando a quantidade de empresas que forneceram informações coerentes com cada um dos atributos de qualidade.

\begin{tabular}{|c|c|c|c|c|c|c|c|c|c|c|c|}
\hline \multirow{2}{*}{ Indicador } & \multicolumn{3}{|c|}{ Compreensibilidade } & \multicolumn{2}{|c|}{ Integridade } & \multicolumn{3}{|c|}{ Neutralidade } & \multicolumn{3}{|c|}{ Comparabilidade } \\
\hline & $\mathbf{a}$ & b & c & d & $\mathbf{e}$ & $\mathbf{F}$ & $\mathbf{G}$ & $\mathbf{H}$ & I & $\mathbf{j}$ & $\mathbf{K}$ \\
\hline EN1 & 20 & 18 & 19 & 5 & 15 & 20 & 13 & 20 & 14 & 0 & 1 \\
\hline EN2 & 15 & 14 & 21 & 12 & 13 & 20 & 10 & 20 & 11 & 0 & 0 \\
\hline EN3 & 27 & 27 & 27 & 26 & 25 & 28 & 22 & 28 & 23 & $\overline{0}$ & 2 \\
\hline EN4 & 26 & 26 & 26 & 23 & 25 & 26 & 21 & 26 & 23 & 0 & 4 \\
\hline EN5 & 20 & 16 & 23 & 14 & 16 & 20 & 4 & 17 & 14 & 1 & 1 \\
\hline EN6 & 18 & 12 & 20 & 6 & 9 & 17 & 3 & 15 & 9 & 0 & 0 \\
\hline EN7 & 14 & 13 & 14 & 4 & 8 & 13 & 1 & 13 & 11 & 1 & 0 \\
\hline EN8 & 29 & 27 & 29 & 26 & 27 & 29 & 21 & 28 & 27 & 2 & 3 \\
\hline EN9 & 7 & 7 & 7 & 6 & 6 & 7 & 1 & 7 & 4 & 0 & 0 \\
\hline EN10 & 18 & 15 & 19 & 14 & 16 & 17 & 6 & 17 & 15 & 0 & 1 \\
\hline EN11 & 22 & 20 & 23 & 12 & 13 & 22 & 2 & 22 & 20 & $\overline{0}$ & 2 \\
\hline EN12 & 14 & 11 & 17 & 4 & 7 & 10 & 0 & 9 & 7 & 0 & 0 \\
\hline EN13 & 19 & 19 & 19 & 17 & 17 & 18 & 5 & 18 & 16 & 0 & 3 \\
\hline EN14 & 14 & 12 & 14 & 10 & 10 & 14 & 0 & 14 & 11 & 0 & 1 \\
\hline EN15 & 9 & 9 & 9 & 8 & 8 & 9 & 1 & 9 & 9 & 0 & 0 \\
\hline EN16/EN17 & 31 & 32 & 29 & 23 & 27 & 32 & 25 & 32 & 32 & 1 & 0 \\
\hline EN18 & 22 & 20 & 22 & 14 & 16 & 23 & 1 & 22 & 16 & 0 & 4 \\
\hline EN19 & 10 & 11 & 10 & 4 & 9 & 12 & 6 & 12 & 4 & 0 & 0 \\
\hline EN20 & 13 & 13 & 13 & 12 & 12 & 13 & 6 & 13 & 12 & 0 & 1 \\
\hline EN21 & 12 & 13 & 13 & 9 & 12 & 13 & 9 & 13 & 11 & 0 & 1 \\
\hline EN22 & 29 & 28 & 30 & 21 & 22 & 26 & 13 & 25 & 28 & 0 & 4 \\
\hline EN23 & 16 & 16 & 16 & 15 & 15 & 16 & 5 & 16 & 16 & 0 & 0 \\
\hline EN24 & 6 & 9 & 7 & 5 & 6 & 9 & 3 & 9 & 6 & 0 & 0 \\
\hline EN25 & 8 & 8 & 11 & 7 & 8 & 8 & 0 & 8 & 9 & 1 & 0 \\
\hline EN26 & 25 & 23 & 26 & 7 & 12 & 17 & 1 & 15 & 23 & $\overline{0}$ & 0 \\
\hline EN27 & 7 & 1 & 7 & 0 & 0 & 3 & 1 & 3 & 3 & 0 & 0 \\
\hline EN28 & 25 & 24 & 25 & 24 & 24 & 24 & 8 & 24 & 24 & $\overline{0}$ & 0 \\
\hline EN29 & 19 & 15 & 18 & 6 & 11 & 15 & 2 & 13 & 13 & 0 & 0 \\
\hline EN30 & 25 & 25 & 25 & 19 & 23 & 25 & 18 & 25 & 25 & 0 & 1 \\
\hline
\end{tabular}

Figura 5. Quantidade de relatórios em conformidade com os atributos de qualidade nos trinta indicadores

Fonte: Elaborado pela pesquisadora

Nota: a) Informação simples, clara, fácil de compreender. b) A informação responde a questão específica do indicador. c) Não apresenta vocabulário técnico ou termos desconhecidos. d) A informação contempla todos os elementos do indicador. e) Não são omitidos dados relevantes. f) São evidenciados aspectos favoráveis e desfavoráveis. g) São apresentadas tendências do indicador ano a ano. h) Questões positivas e negativas enfatizadas em igual medida. i) É possível comparar com outras empresas do setor. j) São reportados benchmarks com o setor, mercado etc. k) São reportadas metas quantitativas e seu nível de atendimento.

Revista de Gestão Social e Ambiental - RGSA, São Paulo, v. 8, n. 1, p. 2-19, jan./abr., 2014. 
Notou-se que, logicamente, é dada maior importância à evidenciação de indicadores considerados essenciais, já que eles representam os principais resultados do desempenho ambiental das empresas, além de serem aplicáveis a todos os setores de atuação. Observou-se também que, especificamente, os indicadores que apresentaram um maior nível de qualidade foram aqueles que informaram sobre as emissões de gases de efeito estufa (EN16 e EN17); isto, porque a maior parte das organizações relataram as emissões de acordo com a classificação do Greenhouse Gas Protocol (GHG Protocol), o que facilitou a comparação dos dados e provocou uma sorte de padronização na evidenciação da informação. Além das tabelas, quadros ou gráficos com os correspondentes valores, de modo geral, as empresas apresentaram as fontes das emissões em detalhes e explicaram, ainda, o porquê dos aumentos ou reduções das emissões de um ano para o outro.

A disposição dos resíduos (EN22) também teve um alto grau de evidenciação; sendo que a maioria dos relatórios forneceu informações de forma compreensível e neutra. $\mathrm{O}$ indicador sobre o consumo de água (EN8) resultou um dos mais simples de ser compreendido, bem como um dos mais objetivos nas afirmações. A forma de apresentação variou desde simples textos até tabelas e gráficos de barras com o consumo por um período de vários anos. Além de apresentar as informações de forma compreensível, o geral das empresas mostrou neutralidade ao informar se houve aumento ou redução no consumo de água, e, até mesmo, algumas explicaram o porquê do maior ou menor consumo.

Já no que respeita aos indicadores que satisfizeram em menor medida os atributos de qualidade destacam-se o EN9 (fontes de água afetadas); a análise deste indicador ficou limitada às poucas empresas que o relataram, e quando informado casos de fontes afetadas, os dados fornecidos não foram completos, não tendo sido explicitadas questões qualitativas, como o nível de biodiversidade afetado. Outros indicadores com baixa aderência pelas empresas foram o EN15 (espécies na Lista Vermelha), e o EN24 (resíduos perigosos), podendo isso se dever à irrelevância destes ou à dificuldade de avaliá-los.

Além disso, foi possível realizar também algumas distinções sobre aqueles relatórios que demonstraram uma maior capacidade para informar aos leitores seu desempenho ambiental. Nesse sentido, os relatórios que encabeçaram o grupo mostrando-se em um nível superior de evidenciação, foram os da Fibria e da Natura, os quais mostraram informações completas, compreensíveis e comparáveis no relato dos indicadores referentes a todos os aspectos ambientais, além de confiáveis, já que ambos possuem um nível de aplicação A+, ou seja, passaram por verificação externa. A Natura se destacou por interpretar e apresentar satisfatoriamente tanto os pontos altos quanto os fracos da sua gestão, sempre mostrando a evolução do seu desempenho ao longo dos anos. A Fibria conseguiu contextualizar os indicadores apresentando-os de forma compreensível e com informações bastante detalhadas para os leitores.

Os relatórios da Coelce e da Cemig, por sua vez, apresentaram indicadores íntegros e neutros relacionados às suas questões materiais (consumo de água e energia, eficiência energética, biodiversidade), apresentando informações comparáveis com outras empresas de energia elétrica. Embora, no geral, os relatórios não tenham se destacado na apresentação de metas, a Tractebel e a Vale reportaram várias metas de desempenho reais e concretas, e sua apresentação se mostrou acessível em tabelas completas, com prazos de atendimento, observações e nível de atendimento das metas.

Com base nos resultados da análise, foi possível identificar os atributos que se mostraram comprometidos para cada um dos indicadores analisados. Nesse sentido, por meio do quadro seguinte, se pretende mostrar um panorama geral das limitações achadas nos indicadores analisados, além de propor algumas melhorias que permitam o aprimoramento na qualidade da informação.

Revista de Gestão Social e Ambiental - RGSA, São Paulo, v. 8, n. 1, p. 2-19, jan./abr., 2014. 


\begin{tabular}{|c|c|c|c|c|c|}
\hline \multirow[t]{2}{*}{ Indicador } & \multicolumn{4}{|c|}{$\begin{array}{c}\text { Atributos } \\
\text { comprometidos }\end{array}$} & \multirow[t]{2}{*}{ Oportunidade de melhoria } \\
\hline & 1 & 2 & $\mathbf{3}$ & 4 & \\
\hline $\begin{array}{l}\text { EN1-Materiais usados por peso ou } \\
\text { volume }\end{array}$ & & $\mathbf{X}$ & & $\mathbf{X}$ & $\begin{array}{l}\text { Contextualizar o indicador, reportar toda a informação } \\
\text { solicitada/ apresentar benchmark com o setor. }\end{array}$ \\
\hline $\begin{array}{l}\text { EN2-Percentual dos materiais usados } \\
\text { provenientes de reciclagem }\end{array}$ & & & $\mathbf{X}$ & $\mathbf{X}$ & $\begin{array}{l}\text { Reportar exatamente a informação solicitada pelo } \\
\text { indicador e as tendências/ apresentar benchmarks } \\
\text { internos e externos. }\end{array}$ \\
\hline $\begin{array}{l}\text { EN3-Consumo de energia direta } \\
\text { discriminada por fonte }\end{array}$ & & & & $\mathbf{X}$ & $\begin{array}{l}\text { Contextualizar o indicador/ apresentar benchmarks } \\
\text { internos e externos. }\end{array}$ \\
\hline $\begin{array}{l}\text { EN4-Consumo de energia indireta } \\
\text { discriminada por fonte }\end{array}$ & & & & $\mathbf{X}$ & $\begin{array}{l}\text { Contextualizar o indicador/ apresentar benchmark com } \\
\text { o setor e metas. }\end{array}$ \\
\hline $\begin{array}{l}\text { EN5-Energia economizada devido a } \\
\text { melhorias }\end{array}$ & & & $\mathbf{X}$ & $\mathbf{X}$ & $\begin{array}{l}\text { Reportar as tendências anuais/ apresentar metas } \\
\text { quantitativas e benchmarks. }\end{array}$ \\
\hline $\begin{array}{l}\text { EN6-Iniciativas para fornecer } \\
\text { produtos com baixo consumo de } \\
\text { energia }\end{array}$ & & $\mathbf{X}$ & $\mathbf{X}$ & $\mathbf{X}$ & $\begin{array}{l}\text { Reportar toda a informação solicitada junto com as } \\
\text { tendências anuais/ apresentar benchmark externo e } \\
\text { metas quantitativas. }\end{array}$ \\
\hline $\begin{array}{l}\text { EN7-Iniciativas para reduzir o } \\
\text { consumo de energia indireta e as } \\
\text { reduções obtidas }\end{array}$ & & $\mathbf{X}$ & $\mathbf{X}$ & $\mathbf{X}$ & $\begin{array}{l}\text { Reportar toda a informação solicitada junto com as } \\
\text { tendências anuais/ apresentar benchmark externo e } \\
\text { metas quantitativas. }\end{array}$ \\
\hline EN8-Total de retirada de água & & & & $\mathbf{X}$ & Apresentar benchmark com o setor e metas. \\
\hline $\begin{array}{l}\text { EN9-Fontes hídricas } \\
\text { significativamente afetadas }\end{array}$ & $\mathbf{X}$ & $\mathbf{X}$ & $\mathbf{X}$ & $\mathbf{X}$ & $\begin{array}{l}\text { Contextualizar o indicador, reportar toda a informação } \\
\text { solicitada/ apresentar benchmark com o setor. }\end{array}$ \\
\hline $\begin{array}{l}\text { EN10-Percentual e volume de água } \\
\text { reciclada/reutilizada }\end{array}$ & & & $\mathbf{X}$ & $\mathbf{X}$ & $\begin{array}{l}\text { Reportar as tendências anuais/ apresentar metas } \\
\text { quantitativas e benchmarks. }\end{array}$ \\
\hline $\begin{array}{l}\text { EN11-Localização da área possuída } \\
\text { dentro de áreas protegidas }\end{array}$ & & & $\mathbf{X}$ & $\mathbf{X}$ & $\begin{array}{l}\text { Reportar as tendências anuais/ apresentar metas } \\
\text { quantitativas e benchmarks. }\end{array}$ \\
\hline $\begin{array}{l}\text { EN12-Descrição de impactos } \\
\text { significativos na biodiversidade }\end{array}$ & & $\mathbf{X}$ & $\mathbf{X}$ & $\mathbf{X}$ & $\begin{array}{l}\text { Reportar informação completa, equilibrada e } \\
\text { comparável/ apresentar metas quantitativas e } \\
\text { benchmarks. }\end{array}$ \\
\hline $\begin{array}{l}\text { EN13-Habitats protegidos ou } \\
\text { restaurados }\end{array}$ & & & $\mathbf{X}$ & $\mathbf{X}$ & $\begin{array}{l}\text { Reportar as tendências anuais/ apresentar metas } \\
\text { quantitativas e benchmarks. }\end{array}$ \\
\hline $\begin{array}{l}\text { EN14-Estratégias para a gestão de } \\
\text { impactos na biodiversidade }\end{array}$ & & & $\mathbf{X}$ & $\mathbf{X}$ & $\begin{array}{l}\text { Reportar as tendências anuais/ apresentar metas } \\
\text { quantitativas e benchmarks. }\end{array}$ \\
\hline $\begin{array}{l}\text { EN15-Número de espécies na Lista } \\
\text { Vermelha da IUCN }\end{array}$ & $\mathbf{X}$ & $\mathbf{X}$ & $\mathbf{X}$ & $\mathbf{X}$ & $\begin{array}{l}\text { Contextualizar o indicador, reportar toda a informação } \\
\text { solicitada/ apresentar benchmarks. }\end{array}$ \\
\hline $\begin{array}{l}\text { EN16 e EN17-Emissões diretas e } \\
\text { indiretas de gases de efeito estufa }\end{array}$ & & & & $\mathbf{X}$ & $\begin{array}{l}\text { Apresentar benchmarks com valores externos e metas } \\
\text { quantitativas. }\end{array}$ \\
\hline $\begin{array}{l}\text { EN18-Iniciativas para reduzir as } \\
\text { emissões de GEE }\end{array}$ & & & $\mathbf{X}$ & $\mathbf{X}$ & $\begin{array}{l}\text { Reportar as tendências anuais/ apresentar metas } \\
\text { quantitativas e benchmarks. }\end{array}$ \\
\hline $\begin{array}{l}\text { EN19-Emissões de substâncias } \\
\text { destruidoras da camada de ozônio }\end{array}$ & & $\mathbf{X}$ & $\mathbf{X}$ & $\mathbf{X}$ & $\begin{array}{l}\text { Reportar a informação completa/ apresentar as } \\
\text { tendências, metas quantitativas e benchmarks. }\end{array}$ \\
\hline $\begin{array}{l}\text { EN20-NOx, SOx e outras emissões } \\
\text { atmosféricas significativas }\end{array}$ & & & $\mathbf{X}$ & $\mathbf{X}$ & $\begin{array}{l}\text { Reportar as tendências anuais/ apresentar metas } \\
\text { quantitativas e benchmarks. }\end{array}$ \\
\hline $\begin{array}{l}\text { EN21-Descarte total de água, por } \\
\text { qualidade e destinação. }\end{array}$ & & $\mathbf{X}$ & $\mathbf{X}$ & $\mathbf{X}$ & $\begin{array}{l}\text { Reportar a informação completa/ apresentar as } \\
\text { tendências, metas quantitativas e benchmarks. }\end{array}$ \\
\hline $\begin{array}{l}\text { EN22-Peso total de resíduos, por tipo } \\
\text { e método de disposição. }\end{array}$ & & & & $\mathbf{X}$ & $\begin{array}{l}\text { Apresentar benchmarks com valores externos e metas } \\
\text { quantitativas. }\end{array}$ \\
\hline $\begin{array}{l}\text { EN23-Número e volume total de } \\
\text { derramamentos significativos. }\end{array}$ & & & $\mathbf{X}$ & $\mathbf{X}$ & $\begin{array}{l}\text { Reportar as tendências anuais/ apresentar metas } \\
\text { quantitativas e benchmarks. }\end{array}$ \\
\hline $\begin{array}{l}\text { EN24-Peso de resíduos perigosos } \\
\text { importados, tratados, transportados, } \\
\text { exportados. }\end{array}$ & $\mathbf{X}$ & $\mathbf{X}$ & $\mathbf{X}$ & $\mathbf{X}$ & $\begin{array}{l}\text { Reportar a informação completa, com clareza e } \\
\text { equilíbrio que viabilize a comparação com as demais } \\
\text { organizações. Apresentar benchmarks. }\end{array}$ \\
\hline $\begin{array}{l}\text { EN25-Identificação, tamanho de } \\
\text { corpos d'água afetados por descartes. }\end{array}$ & $\mathbf{X}$ & $\mathbf{X}$ & $\mathbf{X}$ & $\mathbf{X}$ & $\begin{array}{l}\text { Apresentar informação completa e neutra sobre a } \\
\text { magnitude do impacto. Apresentar benchmarks. }\end{array}$ \\
\hline $\begin{array}{l}\text { EN26-Iniciativas para mitigar os } \\
\text { impactos ambientais de produtos e } \\
\text { serviços. }\end{array}$ & & $\mathbf{X}$ & $\mathbf{X}$ & $\mathbf{X}$ & $\begin{array}{l}\text { Reportar toda a informação solicitada junto com as } \\
\text { tendências anuais/ apresentar benchmark externo e } \\
\text { metas quantitativas. }\end{array}$ \\
\hline $\begin{array}{l}\text { EN27-Percentual de embalagens } \\
\text { recuperadas em relação às vendidas. }\end{array}$ & $\mathbf{X}$ & $\mathbf{X}$ & $\mathbf{X}$ & $\mathbf{X}$ & $\begin{array}{l}\text { Reportar a informação completa, com clareza e } \\
\text { equilíbrio que viabilize a comparação com as demais }\end{array}$ \\
\hline
\end{tabular}

Revista de Gestão Social e Ambiental - RGSA, São Paulo, v. 8, n. 1, p. 2-19, jan./abr., 2014. 


\begin{tabular}{|l|l|l|l|l|l|}
\hline & & & & & organizações. Apresentar benchmarks. \\
\hline EN28-Valor monetário de multas. & & & $\mathbf{X}$ & $\mathbf{X}$ & $\begin{array}{l}\text { Reportar as tendências anuais/ apresentar metas } \\
\text { quantitativas e benchmarks. }\end{array}$ \\
\hline $\begin{array}{l}\text { EN29-Impactos ambientais de } \\
\text { transporte de produtos e } \\
\text { trabalhadores. }\end{array}$ & & $\mathbf{X}$ & $\mathbf{X}$ & $\mathbf{X}$ & $\begin{array}{l}\text { Reportar toda a informação solicitada junto com as } \\
\text { tendências anuais/ apresentar benchmark externo e } \\
\text { metas quantitativas. }\end{array}$ \\
\hline $\begin{array}{l}\text { EN30-Investimentos e gastos em } \\
\text { proteção ambiental. }\end{array}$ & & & $\mathbf{X}$ & $\begin{array}{l}\text { Apresentar benchmarks com valores externos e metas } \\
\text { quantitativas. }\end{array}$ \\
\hline
\end{tabular}

Figura 6. Atributos de qualidade comprometidos nos indicadores

Fonte: Elaborado pela pesquisadora

Nota: 1. Compreensibilidade. 2. Integridade. 3. Neutralidade. 4. Comparabilidade.

Na figura anterior, observa-se que, de modo geral, o atributo de compreensibilidade mostrouse presente nos relatos dos indicadores, isso quer dizer que a maioria das empresas soube interpretar as explicações fornecidas pela diretriz e evidenciar claramente os dados correspondentes. Cabe ressaltar, que muitas destas empresas vêm publicando seus relatórios em concordância com a diretriz GRI há vários anos, portanto já estão familiarizadas com cada um dos indicadores.

Entretanto, percebe-se que o atributo de qualidade mais comprometido nas evidenciações dos 30 indicadores foi a comparabilidade, principalmente em decorrência da constante omissão de benchmarks e da comparação do desempenho real com metas previamente definidas. $\mathrm{O}$ atributo de neutralidade se apresentou insuficientemente atendido em muitos indicadores em razão da impossibilidade de verificar suas tendências. Este fato resultou curioso, já que todas essas empresas apresentam demonstrativos contábeis com seus respectivos comparativos de anos anteriores, portanto esperava-se que o mesmo acontecesse nos relatórios de sustentabilidade, especialmente no caso de indicadores quantitativos. A integridade da informação também se viu afetada em alguns indicadores, geralmente naqueles mais robustos, de natureza qualitativa e quantitativa, sendo que alguns dados resultaram descuidados ou, no pior dos casos, eliminados.

\section{CONSIDERAÇÕES FINAIS}

Este trabalho pretendeu fornecer alguns insights da qualidade dos indicadores de desempenho ambiental, evidenciados nos relatórios de sustentabilidade de um grupo de empresas brasileiras de prestigiado nível econômico e ambiental. Logo, de uma leitura crítica, algumas considerações podem ser feitas sobre os indicadores analisados.

O fato de as organizações prepararem seus relatórios com base na diretriz GRI é considerado um acontecimento positivo, já que esta diretriz abrange uma ampla gama de aspectos relevantes que, em seu conjunto, podem brindar os stakeholders com uma ideia da performance ambiental das organizações. Não obstante, cabe às organizações saber interpretar os indicadores propostos e informá-los de um modo que seja acessível e credível para os leitores. Os resultados da análise sugeriram que essa situação nem sempre se cumpre, apontando para um necessário aprimoramento da evidenciação do desempenho ambiental.

Da grande família de indicadores ambientais analisados, a partir das próprias características deles, e, dos resultados obtidos, foi possível dividi-los em três grupos, a saber: (1) Indicadores predominantemente quantitativos - consumo de materiais, de energia, e de água; tamanho da área possuída; total de emissões de GEE; peso dos resíduos; valor monetário de multas e de investimentos em proteção ambiental -; (2) Indicadores sobre os impactos ambientais, predominantemente qualitativos - impactos na biodiversidade; qualidade do descarte de água; impactos do transporte - e; (3) Indicadores sobre as iniciativas para reduzir os impactos, qualitativos e quantitativos - iniciativas para reduzir o consumo de energia; para a gestão de impactos na biodiversidade; para reduzir as emissões de GEE; para mitigar os impactos ambientais de produtos e serviços -.

Da análise teve-se que, aqueles indicadores incluídos no item (1) demonstraram ser os mais claros, objetivos, completos e comparáveis do grupo. Tratando-se de valores quantitativos, 
observou-se uma maior uniformidade nas evidenciações; além disso, esses indicadores foram apresentados por vários períodos, sendo evidenciadas, também, as metas traçadas em torno deles, principalmente no que diz respeito à redução do consumo de recursos. Não obstante isso, a apresentação de dados isolados, sem a contextualização da sua relevância, não permitiu demonstrar, claramente, a situação na qual se encontram as organizações individualmente. De modo geral, a comparação dos indicadores com valores tidos como referência resultou deficitária, uma vez que, apenas seis benchmarks foram apresentados em todos os documentos analisados.

Quanto aos indicadores contidos no item (2), as informações reveladas foram menos concretas e completas que aquelas dos indicadores anteriores. De modo geral, questões sobre os impactos foram apenas mencionadas, de forma vaga, sem explicações sobre a gravidade deles, o estágio de mitigação alcançado, e quanto ainda falta por fazer para reconstituir os danos ocasionados. Além dessas informações, um elemento importante foi quase totalmente excluído nas evidenciações, a evolução dos impactos ao longo dos anos. É de se destacar, que, dados concisos sobre a relevância dos impactos ambientais constituem uma das maiores preocupações dos stakeholders, mesmo assim, a ausência desse tipo de informação se fez evidente nos relatórios. A falta de informação aprofundada, para esses indicadores, pôde ter sido devido a diferentes motivos, como a dificuldade em avaliar os impactos ambientais; a irrelevância dessas informações para as organizações; ou a decisão dos gestores de não correr o risco de publicar informação negativa que possa desprestigiar a imagem das empresas.

Já, no que diz respeito à análise dos indicadores do item (3), os resultados mostraram que, embora a compreensão e a integridade estivessem presentes nos dados evidenciados, uma informação relevante foi omitida, refere-se ao estabelecimento e à conquista de metas. Esses indicadores, justamente, representam as iniciativas implantadas para minimizar os impactos, portanto, devem informar sobre os compromissos assumidos pelas organizações, e em que medida esses compromissos estão sendo cumpridos. Uma vez que essas iniciativas devem fazer parte do plano estratégico de cada organização, é de se esperar que elas sejam operacionalizadas por meio de metas objetivas de curto prazo. Assim, chamou a atenção que esses dados que dão suporte para as iniciativas programadas, praticamente, não tenham sido revelados, privando ao leitor de conhecer se os objetivos propostos foram alcançados satisfatoriamente.

De modo geral, os resultados mostraram que, as organizações tendem a evidenciar com maior qualidade informações que demonstrem as atividades realizadas em prol da sustentabilidade, enquanto tentam fugir dos indicadores que questionam acerca da gravidade dos impactos ambientais ocasionados, o que se condize com os achados de Leszczynska (2012). Isso aponta que, fornecer informação com ênfase na prestação de contas, por meio de dados objetivos e relevantes para todos os públicos, e não meras afirmações superficiais sobre a sustentabilidade; continua sendo um grande desafio para as organizações. Desse modo, a insatisfação geral dos stakeholders também foi percebida por meio da leitura dos relatórios. Em alguns apartados desses documentos, transcenderam as demandas de informação não satisfeitas, principalmente no que se refere à magnitude dos impactos e às metas, demandas que os próprios stakeholders fizeram às organizações, e que estas publicaram nos relatórios. Isso demonstra que têm empresas preocupadas com os interesses dos seus públicos, e visam lograr um relatório de sustentabilidade de excelência, mas ainda não chegaram lá.

Um inconveniente, ainda percebido, consistiu na falta de padronização da evidenciação dos indicadores, em que tabelas, gráficos, textos, figuras foram misturados. Essa falta de uniformidade acabou por dificultar a comparação entre relatórios, limitação apontada também na análise de relatórios feita pela KPMG (2011). Além disso, o nível de desdobramento da informação variou entre relatórios e entre indicadores. Assim, enquanto alguns relatórios forneciam dados apenas quantitativos para um indicador, outros complementavam a informação com exemplos qualitativos. Essas diferenças são admissíveis, já que a diretriz GRI bem definiu o conteúdo do relatório, o que é um grande avanço para esse tipo de informação, mas não definiu a formatação dos dados evidenciados. É possível que, daqui a uns anos, seja determinado um formato padrão para 
apresentação desses indicadores. Por enquanto, são as organizações que devem estar atentas para definir o melhor modo de apresentar suas informações e que estas resultem comparáveis entre si.

Cabe esclarecer que, nesta pesquisa, não foi discutida a supremacia dos indicadores da GRI, com o fim de concluir se estes são os mais adequados para se obter um conhecimento certeiro do desempenho ambiental das organizações, ou se, pelo contrário, é preciso modificá-los ou adicionar novos indicadores a este conjunto. Considerada sua alta aderência internacional, pareceria que esta diretriz para relatórios de sustentabilidade se erige como a mais aceita entre as empresas e a comunidade científica, no entanto, no decorrer da análise, na busca de informações de qualidade, inevitavelmente, reluziram alguns pontos que fizeram questionar elementos de certos indicadores.

Uma importante limitação encontrada foi o fato de muitos aspectos da sustentabilidade serem medidos por meio de indicadores absolutos, e, apesar de sua finalidade ser a avaliação da magnitude dos impactos, sem outras medidas com que comparar estes valores, dificulta compreender seu nível de gravidade. Para dar suporte a esses resultados, buscaram-se nos relatórios comparativos com valores de anos anteriores, metas predefinidas e pontos de referência externos que serviriam de parâmetros para auxiliar na contextualização da situação. Porém, a evidenciação de benchmarks se mostrou muito insatisfatória, e mesmo as tendências tendo sido apresentadas em maior medida, estas não pareceram ser suficientes para avaliar os desempenhos.

Além desse, outro obstáculo para avaliar a situação ambiental das organizações, consistiu no fato de a diretriz avaliar apenas o desempenho ambiental do ano considerado base para a elaboração do relatório e o cálculo dos indicadores. Como apontado por Isaksson e Steimle (2009), contar simplesmente com esses dados não parece ser suficiente para responder a questão de em qual estágio de (in)sustentabilidade se encontram as organizações, uma vez que nem sempre todas elas aportam informação referente aos resultados dos períodos anteriores.

De forma ampla, pode-se dizer que a evidenciação do desempenho ambiental das organizações brasileiras tem percorrido um longo caminho até hoje, e, com certeza, tem evoluído em quantidade e qualidade, mas muito empenho ainda é preciso para alcançar um nível de excelência e transparência da informação, em concordância com os atributos de qualidade. É importante que as organizações continuem trabalhando para garantir a clareza, o equilíbrio e a relevância das informações divulgadas, e fazer, assim, com que os leitores compreendam e acreditem no compromisso com o meio ambiente, que elas tentam transmitir.

Futuras pesquisas sobre indicadores de desempenho e relatórios de sustentabilidade são relevantes, na tentativa de incrementar a qualidade das informações sobre a sustentabilidade. Tais pesquisas podem incluir análises dos demais indicadores de desempenho, tais como os econômicos ou os sociais, visando verificar o nível de qualidade na evidenciação destes; comparações com os indicadores de desempenho ambiental evidenciados por empresas internacionais; pesquisas sobre as demandas de informação dos stakeholders e a sua percepção sobre as evidenciações do desempenho ambiental das organizações.

\section{REFERÊNCIAS}

Accountability.(2008) AA1000 Accountability Principles Standard.

Aerts, W., Cormier, D.(2009) Media legitimacy and corporate environmental communication. Accounting, Organizations and Society, 34, 1-27.

Azzone, G., Brophy, M., Noci, G., Welford, R., Young, W.(1997) A stakeholders' view of environmental reporting. Long Range Planning, 30(5), 699-709.

Beloff, B., Beaver, E.(2000) Sustainability indicators and metrics of industrial performance. In: The SPE International Conference on Health, Safety, and Environment in Oil and Gas Exploration and Production, Stavanger, Norway.

Christofi, A., Christofi, P., Sisaye, S. (2012) Corporate sustainability: historical development and reporting practices. Management Research Review, 35(2), 157-172.

Revista de Gestão Social e Ambiental - RGSA, São Paulo, v. 8, n. 1, p. 2-19, jan./abr., 2014. 
Cho, C.H., Roberts, R.W., Patten, D.M.(2010) The language of US corporate environmental disclosure. Accounting, Organizations and Society, 35, 431-443.

Corporate Register.(2011) CR Reporting Awards'11. London.

Daub, C-H.(2007) Assessing the quality of sustainability reporting: an alternative methodological approach. Journal of Cleaner Production, 15, 75-85.

Dawkins, C.E., Fraas, J.W.(2011) Erratum to: beyond acclamations and excuses: Environmental performance, voluntary environmental disclosure and the role of visibility. Journal of business ethics, 99(3), 383-397.

Dierkes, M., Preston, L.E.(1977) Corporate social accounting reporting for the physical environment: A critical review and implementation proposal. Accounting, Organizations and Society, 2(1), 3-22.

Epstein, M.J.(2008) Making sustainability work: best practices in managing and measuring corporate social, environmental, and economic impacts. San Francisco: Greenleaf Publishing.

Global Reporting Initiative (GRI, 2014) Recuperado em: 2014, de:

<https://www.globalreporting.org>.

Global Reporting Initiative (GRI, 2014) Diretrizes para Relatório de Sustentabilidade - Versão 3.0.

Global Reporting Initiative (GRI) Conjunto de Protocolos de Indicadores de Meio Ambiente, versão GRI G3. Recuperado em: Agosto de 2012, de: < http://www.globalreporting.org>.

Gray, R.(2006) Social, environmental and sustainability reporting and organizational value creation? Whose value? Whose creation? Accounting, Auditing \& Accountability Journal, 19 (6), 793-819.

Hopwood, A.G.(2009) Accounting and the environment. Accounting, Organizations and Society, 34, 433-439.

Hrasky, S.(2012) Visual disclosure strategies adopted by more and less sustainability-driven companies. Accounting Forum, 36, 154- 165.

Isakson, R., Steimle, U.(2009) What does GRI-reporting tell us about corporate sustainability? The TQM Journal, 21(2), 168-181.

Kolk, A.(2004) A decade of sustainability reporting: developments and significance. International Journal of Environment and Sustainable Development, 3(1), 51-64. .(2003) Trends in sustainability reporting by the fortune global 250. Business Strategy and the Environment, 12, 279-291.

KPMG.(2011) KPMG International Survey of Corporate Responsibility Reporting. Recuperado em: Agosto de 2012, de: 〈http://www.kpmg.com>.

Lee, M-D.P.(2011) Configuration of external influences: the combined effects of institutions and stakeholders on corporate social responsibility strategies. Journal of Business Ethics, (102), 281298.

Leszczynska, A.(2012) Towards shareholders' value: an analysis of sustainability reports. Industrial Management \& Data Systems, 112(6), 911-928.

Marshall, R. S., Brown, D.(2003) Corporate environmental reporting: what's in a metric? Business Strategy and the Environment, 12, 87-106. 
Milne, M.J., Tregidga, H., Walton, S.(2009) Words not actions! The ideological role of sustainable development reporting. Accounting, Auditing \& Accountability Journal, 22(8), 1211-1257.

Moldan, B., Janousková, S., Hák, T.(2012) How to understand and measure environmental sustainability: Indicators and targets. Ecological Indicators, 17, 4-13.

Moneva, J.M., Archel, P., Correa, C. (2006) GRI and the camouflaging of corporate unsustainability. Accounting Forum, 30, 121-137.

Olsthoorn, X., Tyteca, D., Wehrmeyer, W., Wagner, M. (2001) Environmental indicators for business: a review of the literature and standardisation methods. Journal of Cleaner Production, 9(5), 453-463.

Organization for Economic Co-operation and Development (OECD, 2004). OECD Principles of Corporate Governance.

Roca, L.C., Searcy, C. (2012) An analysis of indicators disclosed in corporate sustainability reports. Journal of Cleaner Production, 20, 103-118.

Saida, D.(2009) Contribution on the analysis of the environmental disclosure: a comparative study of American and European multinationals. Social Responsibility Journal, 5(1), 83 - 93.

United Nations Conference of Trade and Development (Unctad, 2004) A Manual for the Preparers and Users of Eco-efficiency Indicators. New York e Geneva.

Vormedal, I., Ruud, A.(2009) Sustainability reporting in Norway - an assessment of performance in the context of legal demands and socio-political drivers. Business Strategy and the Environment, $18(4), 201-222$.

Wiseman, J.(1982) An evaluation of environmental disclosures made in corporate annual reports. Accounting, Organizations and Society, 7(1), 53-63.

World Business Council for Sustainable Development (WBCSD, 2002) Sustainable Development Reporting: Striking the Balance. World Business Council for Sustainable Development, Genebra.

Data da submissão: 05/11/2013

Data da publicação: 30/04/2014 